\title{
The Effect of the Polymer Type in the Three-Phases Fischer- Tropsch Synthesis Catalyzed by suspended Iron Nanocatalysts
}

\author{
Abdulqadier H. Al khazraji, Ghalib A. Atiya and Sahar H. Mourad \\ Department of Chemistry, College of Education for Pure Science, University of Diyala, Iraq
}

\begin{abstract}
Fischer-Tropsch synthesis (FTS) was conducted over paraffin-iron catalysts of three phases system with synthetic polymers that contains different compositions. The suspended iron nanocatalyst was introduced into the slurry reactors Fischer-Tropsch with range temperature $(220-320)^{\circ} \mathrm{C}$ at $2.0 \mathrm{MPa}$, the atomic ratio contains: $100 \mathrm{Fe} / 100 \mathrm{Paraffin} / 10 \mathrm{wt} \%$ polymer. The study of phase, structure and morphology of the nanocatalyst using $\mathrm{x}-$ ray diffraction (XRD) and atomic force microscope (AFM) techniques confirmed that there are two phases of iron oxides $\mathrm{Fe}_{3} \mathrm{O}_{4}$ and $\delta$-FeOOH are existed. Maximum conversion of $\mathrm{CO}$ to yields of total liquid hydrocarbons that obtained was $74 \%$ and $62 \mathrm{~g} / \mathrm{m}^{3}$ of FTS over the catalyst Fe-Paraffin/ Polyethylene glycol (Fe-P/PEG) compared to Fe-Paraffin/ Polyethylene terephthalate (Fe-P/PET) and Fe-Paraffin/polycarbonate (Fe-P/PC) systems. The results shows that the polymer type and their structure as well as preparation time of the iron nanocatalysts have high influence on the particle size value. A selectivity of $65 \%$ of syngas converted $\mathrm{C}_{5+}$ liquid hydrocarbons achieved using (Fe-P/PEG) catalyst.
\end{abstract}

Keywords: Fischer-Tropsch synthesis; iron nanocatalysts; polymer; three phase slurry reactors.

\section{Introduction}

More efforts have been made in chemical species of nanometric size during recent years for the purposes of finding specified catalyst for FTS ${ }^{1-4}$. Metal nanoparticles (M-NPs) were used extensively in such research area, this because of special interests of its uses in industry due to the their aptitude of selective catalytic properties and standing properties ${ }^{3,5}$. The particle size represents the key factor in this process of the solid phase of suspension since it can considerably reduce the tendency of the system. Many research paper shows that using metal nanoparticles leads to an increase the activity and selectivity of methane production ${ }^{6,7}$. Nanocatalysts were formed and activated in situ; in the dispersion medium, the properties of these catalysts differ from the conventional catalysts due to the former are inherently colloidal solutions, intermediate between the true solution and suspension. Generally, the issues of formation of nano Fischer-Tropsch catalyst (FTC) under the conditions of a liquid phase are still poorly understood ${ }^{8,9}$.

Some studies reported that the optimal content metal component in the classical three-phase systems (TPS) used in FTS does not exceed 20\% 12. The agglomeration of active metal particles dispersed in a dispersion medium can be solved by the introduction of surfactants or ionic liquids. These methods are unsuitable for the preparation of suspensions synthetic *Corresponding author: Ghalib A. Atiya

Email address: ghalibatiya@gmail.com

DOI: http://dx.doi.org/10.13171/mjc01912021046gaa
FTC, since many stabilizers are composed of components which are also conceded as a catalyst poisons. Recent studies have investigated the effect of polymers on the stability of the system ${ }^{13-15}$.

In the present study, the influence of polymer type on the iron nanocatalyst performance was investigated, also the effect of preparation time and activity on the iron nanoparticles distribution in FTS in a threephase. The FTS performance of iron nanocatalysts was tested in a slurry reactor and correlated with the characterization results.

\section{Materials and Methods}

\subsection{General}

The following compounds were used: Petroleum Paraffin wax type P-2 code: (GOST 23683-89) which is mixture of high molecular weight hydrocarbons of $\mathrm{C}_{18}-\mathrm{C}_{35}$, preferably aliphatic structure, iron (III) nitrate nonahydrate $\left(\mathrm{Fe}\left(\mathrm{NO}_{3}\right)_{3} \cdot 9 \mathrm{H}_{2} \mathrm{O}\right)$ type "extra pure", manufacturer Scharlau Chemie S.A., purified carbon monoxide (CO) supplied directly through pipelines from the decomposition of formic acid in the presence of sulphuric acid. The $\mathrm{CO}$ purification were done by flow the gas through a solution of alkali to get rid of sulphuric acid and carbon dioxide as a by product of the following reaction:

$$
\mathrm{HCOOH} \rightarrow \mathrm{CO}^{\uparrow}+\mathrm{H}_{2} \mathrm{O}
$$


Then the $\mathrm{CO}$ pumped into reservoir cylinders at maximum pressure of $120 \mathrm{~atm}$. Hydrogen $\left(\mathrm{H}_{2}\right)$ gas of technical grade A (GOST 3022-80) supplied locally. Nitrogen $\left(\mathrm{N}_{2}\right)$ gas grade A (TU 6-21-39-96). Then CO and $\mathrm{H}_{2}$ gases mixed to the desired composition in a gasholder to form the synthesis gas then compressed and stored in a buffer tank. For accurate calculation, nitrogen gas added as standard internal indicator to synthetic gas.

The particle size of the synthesized samples was determined by the scattering of dynamic light using Malvern Zetasizer Nano ZS90. To prepare the sample; dissolution of (0.01) $\mathrm{g}$ of the sample in hexane $10 \mathrm{~mL}$, with the addition of sodium dioctyl sodium sulfosuccinate $\left(\mathrm{C}_{20} \mathrm{H}_{38} \mathrm{NaO}_{7} \mathrm{~S}\right) 5 \mathrm{wt} \%$ as a surfactant.

The samples were analyzed by atomic force microscopy (AFM) using an AFM type AFM spectrometer with a PX Ultra multi-frequency controller and a HybriD ${ }^{\mathrm{TM}}$ method controller. The probes: CSG10. Fres $=18.5 \mathrm{kHz}, \mathrm{k}=0.07 \mathrm{~N} / \mathrm{m}$ NSG01. Fres $=187.2 \mathrm{kHz}, \mathrm{k}=3.9 \mathrm{~N} / \mathrm{m}$. All measurements were performed using the Hybrid technique using the DMT model. To determine the nanoparticles in the depth of the samples, the surface layer of paraffin was removed by hexane: the sample was dissolved in hexane to get rid of the wax layer that coats the polymer.

Shimadzu XRD-7000 apparatus using $\mathrm{Cu} \mathrm{Ka}$ radiation, the voltage $40 \mathrm{kV}$, current strength $30 \mathrm{~mA}$, and the scan rate 2 seconds.

The leaving gas from the reactor including nitrogen, were unreacted carbon monoxide, hydrogen and alkanes and olefins $\left(\mathrm{C}_{1}-\mathrm{C}_{4}\right)$. The analysis of the initial substances and gaseous products was carried out by gas-solid chromatography using a "Kristallyuks$4000 \mathrm{M} "$ with a thermal conductivity detector and helium as a carrier gas. Two chromatographic columns were used, $\mathrm{CO}$ and $\mathrm{N}_{2}$ were separated on a 3 $\mathrm{m} \times 3 \mathrm{~mm}$ column packed with $\mathrm{CaA}$ molecular sieves in an isothermal mode at $80^{\circ} \mathrm{C} . \mathrm{CO}_{2}$ and $\mathrm{C}_{1}-\mathrm{C}_{4}$ hydrocarbons were separated on a HayeSep R-packed column $(3 \mathrm{~m} \times 3 \mathrm{~mm})$ with temperature range of (80 to 200$)^{\circ} \mathrm{C}$ programmed at $8^{\circ} \mathrm{C} / \mathrm{min}$.

The CO conversion (\%) and The selectivities (\%) of liquid hydrocarbons $\left(\mathrm{C}_{5+}\right)$ are calculated according to the 16

$$
\begin{aligned}
& \text { CO conversion }(\%)=\frac{\left(\text { Moles } C O_{\text {in }}\right)-\left(\text { Moles } C O_{\text {out }}\right)}{\text { Moles } C O_{\text {in }}} \times 100 \\
& \text { Selectivity of j product }(\%)=\frac{\text { Moles of } j \text { product }}{\left(\text { Moles } C O_{\text {in }}\right)-\left(\text { Moles } C O_{\text {out }}\right)} \times 100
\end{aligned}
$$

The resulted liquid hydrocarbons from the FischerTropsch process contains a mixture of aliphatic saturated and unsaturated hydrocarbons of normal and iso-structure. The amount of unsaturated hydrocarbons in the resulted synthetic products was calculated from the differences in sample volume before and after treatment with concentrated sulfuric acid. The content of olefins was determined by the following formula:

$w_{o l, \%}=\frac{\left(V_{1}-V_{2}\right)}{V_{1}} \cdot \rho \cdot 100 \%$

$-\mathrm{w}_{\mathrm{ol}}, \%$ - mass fraction of olefins in the sample,

$-\mathrm{V}_{1}$ is the sample volume before treatment with sulphuric acid,

$-\mathrm{V}_{2}$ is the volume of the sample after treatment with sulphuric acid,

$-\rho$ is the average density of olefins (assumed to be $0.7 \mathrm{~g} / \mathrm{mL})^{17}$.

The fractional composition of the mixture of liquid hydrocarbons was determined using a "Kristallyuks4000M" chromatograph. The device was monitored and controlled using the special program NetChromWin 2.1. The detector is flame ionization. The feed rate of gases: nitrogen - $30 \mathrm{~mL} / \mathrm{min}$, hydrogen $-25 \mathrm{~mL} / \mathrm{min}$, air $-250 \mathrm{~mL} / \mathrm{min}$. An OV 351 capillary columns ( $50 \mathrm{~m}$ x $0.32 \mathrm{~mm}$ ) was used for the determination. The sample volume is $0.1 \mu 1$, temperature range: $50^{\circ} \mathrm{C}(2 \mathrm{~min})-50-260^{\circ} \mathrm{C}, 6^{\circ} \mathrm{C} / \mathrm{min}$ $-260-270^{\circ} \mathrm{C}, 5^{\circ} \mathrm{C} / \mathrm{min}-270^{\circ} \mathrm{C}, 10 \mathrm{~min}$.

\subsection{General method of preparation iron nanocatalysts}

Paraffin $(100 \mathrm{~mL})$ was warmed to $120^{\circ} \mathrm{C}$, and then the polymer (10 gm, $10 \mathrm{wt} \%)$ was added one portion. Then, the mixture was warmed up to $280^{\circ} \mathrm{C}$, and stirred under inert gas. Aqueous solutions $\mathrm{Fe}$ $\left(\mathrm{NO}_{3}\right)_{3} .9 \mathrm{H}_{2} \mathrm{O}(43.23 \mathrm{~g})$ was dissolved in distillation water $(20 \mathrm{~mL})$ and added dropwise using a funnel. The yield was $100 \mathrm{~mL}$. The following step was loading the suspend nanocatalyst $(100 \mathrm{~mL})$ into Fishcher-Tropsch ractor (slurry reactors) at $2 \mathrm{MPa}$ and a syngas load 1-2 L/(g cat. h) (syngas with a CO: $\mathrm{H}_{2}=1: 1$ molar ratio) in a range of temperature between 220 and $320^{\circ} \mathrm{C}$. Then the temperature gradually increased (about $20^{\circ}$ Cinterval $12 \mathrm{~h}$ ) the system described in details in ref. ${ }^{17}$.

\section{Results and discussion}

\subsection{Particle size distribution}

To test the effect of the catalyst on Fischer Tropsch method, some new catalysts were synthesized. These are including pristine nanocatalyst $\mathrm{Fe}$-paraffin/ Polyethylene glycol (Fe-P/ PEG), Fe paraffin/ Polyethylene terephthalate (Fe-P/ PET) and $\mathrm{Fe}-$ paraffin/ polycarbonate (Fe-P/ PC). The 
synthesized samples have analyzed by dynamic scattering to determine the particle size distribution changes of the dispersed phase of the synthesized suspensions of catalysts. It has found that time preparation can affect the iron nanoparticles size.

Table 1. The effect of polymer type and time preparation on the particle size of the working catalyst.

\begin{tabular}{|c|c|c|c|c|c|c|}
\hline \multirow{2}{*}{$\begin{array}{c}\text { Nanocatalysts } \\
\text { type }\end{array}$} & \multicolumn{5}{|c|}{ Changes in Particles size (nm) of catalyst system over time in hour } \\
\cline { 2 - 7 } & nm at 0 hour & $\begin{array}{c}\text { Weight } \\
\text { content, } \\
\%\end{array}$ & nm at 1 hour & $\begin{array}{c}\text { Weight } \\
\text { content, \% }\end{array}$ & nm at 2hours & $\begin{array}{c}\text { Weight } \\
\text { content, \% }\end{array}$ \\
\hline Fe-P/PEG & 213 & 11 & 232 & 17 & 181 & 9 \\
\hline Fe-P/PET & 779 & 89 & 804 & 83 & 655 & 91 \\
\hline Fe-P/PC & 397 & 100 & 601 & 100 & 212 & 94 \\
\hline
\end{tabular}

From Table 1, the first test shows that time at 0 hour, using PEG leads to the formation of bimodal small and large particle size distribution with a nano iron suspension containing $11 \%, 89 \%$ of particles at 213 $\mathrm{nm}$ and $779 \mathrm{~nm}$. While, after 1 hour the results were $17 \%, 83 \%$ at $232 \mathrm{~nm}$ and $804 \mathrm{~nm}$ respectively. Changing the system such as using PC and PET gave a unimodal particle size distribution with a nano iron suspension containing $100 \%$ of particles of $150 \mathrm{~nm}$ $397 \mathrm{~nm}$ and 434, $601 \mathrm{~nm}$ at 0 and 1 hour respectively. After 2 hours we can see the effect of preparation time on the iron nanocatalyst, especially with using a PC and PET leads to the formation bimodal particle size distribution with iron nanocatalyst suspension containing $6 \%, 94 \%$ of particles at $85 \mathrm{~nm}$ and $212 \mathrm{~nm}$. Based on the results of iron nanoparticles, it is possible that the nanoparticles was distributed between the polymer and paraffin layers. The table indicates that preparation time affected the nanoparticles distribution for Fe-P/ PET and Fe-P/PC as a nanocatalyst after one hour of reaction. As a result both gave small and large nanoparticles distribution

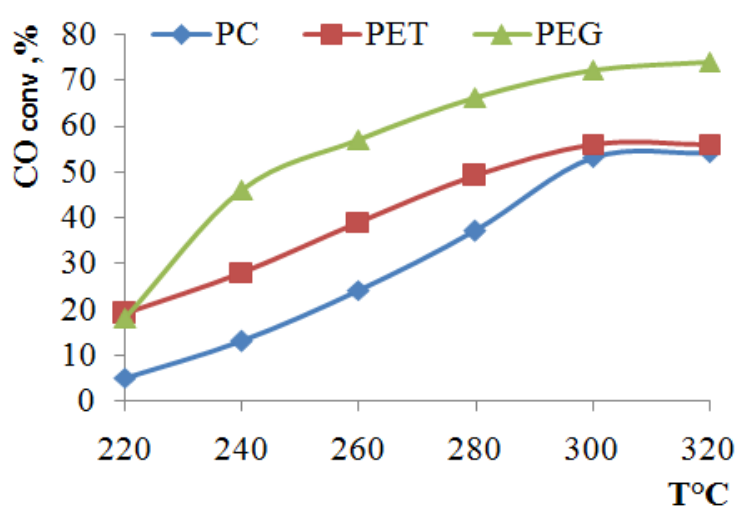

Figure 1.Temperature against $\mathrm{CO}$ conversion

Compared with the us of Fe-paraffin/ PET and Feparaffin/ PC catalyst both decreased the CO conversion to $56 \%, 54 \%$ yield (Figure 1), and the formation of liquid hydrocarbons $54 \mathrm{~g} / \mathrm{m}^{3}, 38 \mathrm{~g} / \mathrm{m}^{3}$ respectively (Figure 2). Rising the $\mathrm{CO}$ conversion after 2 hour between the polymer and paraffin layers, comparing to the beginning preparation time at 0 and 1 hour with a single layer. The obtained data were confirmed by the AFM discussed in Section 3.3.1 below.

The interpretation of the light scattering intensity suggests that larger particles (greater than $397 \mathrm{~nm}$ ) are dominant in the suspension, as well as, the weight content and intensity of these particles is significantly higher than the fraction of nano iron particles with a size of less than $232 \mathrm{~nm}$.

\subsection{FTS performance}

All synthesized catalysts showed active catalytic ( $\mathrm{CO}$ conversion and yield $\mathrm{C}_{5+}$ ) in the preparation of liquid hydrocarbons from $\mathrm{CO}$ and $\mathrm{H}_{2}$ during the process. The introducing of the catalyst Fe-P/ PEG led to get good conversion of $\mathrm{CO}$ gas, significantly up to $74 \%$ of yield (Figure 1), and the formation of liquid hydrocarbons is $62 \mathrm{~g} / \mathrm{m}^{3}$ (Figure 2).

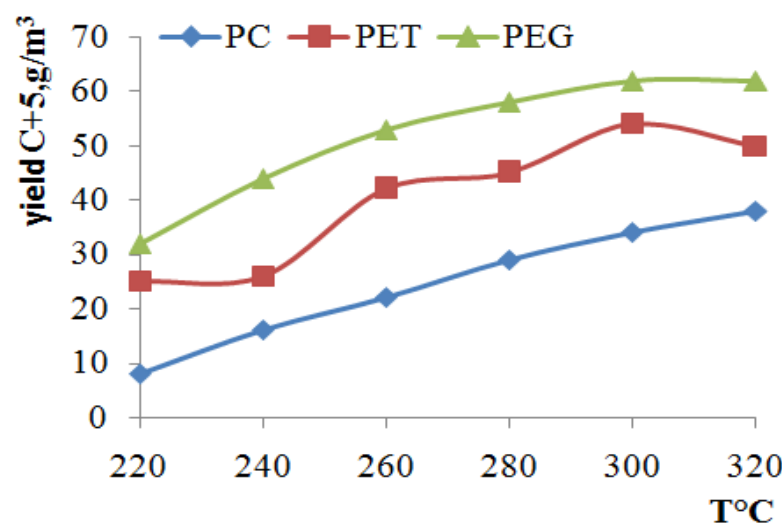

Figure 2. Temperature against the yield of liquid hydrocarbons

using PEG polymer though to be because of the system have a $d$-metal in iron, which has the ability to interact with the unshared pair electrons (in $\mathrm{OH}$ group) via the donor-acceptor mechanism. This fact also can be used to explain the formation of strong 
active centres for adsorption of the synthetic gas ${ }^{18}$. Figure 2 and Table 2 shows that the synthesized products with different polymers have different yields gaseous hydrocarbons depends on the nature of the polymer which required further studies. The $\mathrm{Fe}$ paraffin/PET resulted in the reduction of $\mathrm{CO}_{2}$ gas of liquid hydrocarbons. However, it is essential to note that the yield of the byproducts such as $\left(\mathrm{C}_{1}, \mathrm{C}_{2}-\right.$ $\mathrm{C}_{4}$ and $\mathrm{CO}_{2}$ ) in the presence of iron nanocatalysts of from 220 to $154\left(\mathrm{~g} \cdot \mathrm{m}^{-3}\right)$, whereas its selectivity of liquid hydrocarbons was less than $65 \%$.

Table 2. Products and their percent conversion of FTS catalyzed based on Fe-paraffin-polymers at temperature range $(220-320)^{\circ} \mathrm{C}, \mathrm{P}=20 \mathrm{~atm}$ and syngas ratio $\left(\mathrm{CO}: \mathrm{H}_{2}=1: 1\right)$.

\begin{tabular}{|c|c|c|c|c|c|c|}
\hline \multirow{2}{*}{$\begin{array}{l}\text { Nanocatalysts } \\
\text { type }\end{array}$} & \multirow{2}{*}{$\begin{array}{c}\text { CO } \\
\% \text { Conv. }\end{array}$} & \multicolumn{4}{|c|}{$\begin{array}{c}\text { produced } \\
\text { Hydrocarbon }\left(\mathrm{g} \mathrm{m}^{-3}\right)\end{array}$} & \multirow[t]{2}{*}{$\begin{array}{l}\text { \% selectivity of targeted } \\
\text { liquid hydrocarbons }\end{array}$} \\
\hline & & $\mathrm{C}_{1}$ & $\mathrm{C}_{2}-\mathrm{C}_{4}$ & $\mathrm{C}_{5+}$ & $\mathrm{CO}_{2}$ & \\
\hline Fe-P/PEG & 74 & 37 & 30 & 62 & 214 & 65 \\
\hline Fe- P /PET & 56 & 26 & 27 & 54 & 154 & 49 \\
\hline Fe- P /PC & 54 & 39 & 21 & 38 & 168 & 54 \\
\hline
\end{tabular}

The Fe-paraffin suspensions containing different polymers exhibited different activities and selectivity for the product ${ }^{19-20}$.

The analysis of liquid hydrocarbons at the end of each process obtained at such range of temperature range $(220-320)^{\circ} \mathrm{C}$, confirmed that the polymer type also have an effect on the fractional composition (gasoline C5-C10, kerosene C11-C18 and wax C19+), and on the group composition of liquid production (n-paraffin, isoparaffin and olefin), we can summaries the main variations as below see Figure $3 \mathrm{a}, \mathrm{b}$ and $\mathrm{c}$ and Table 3.
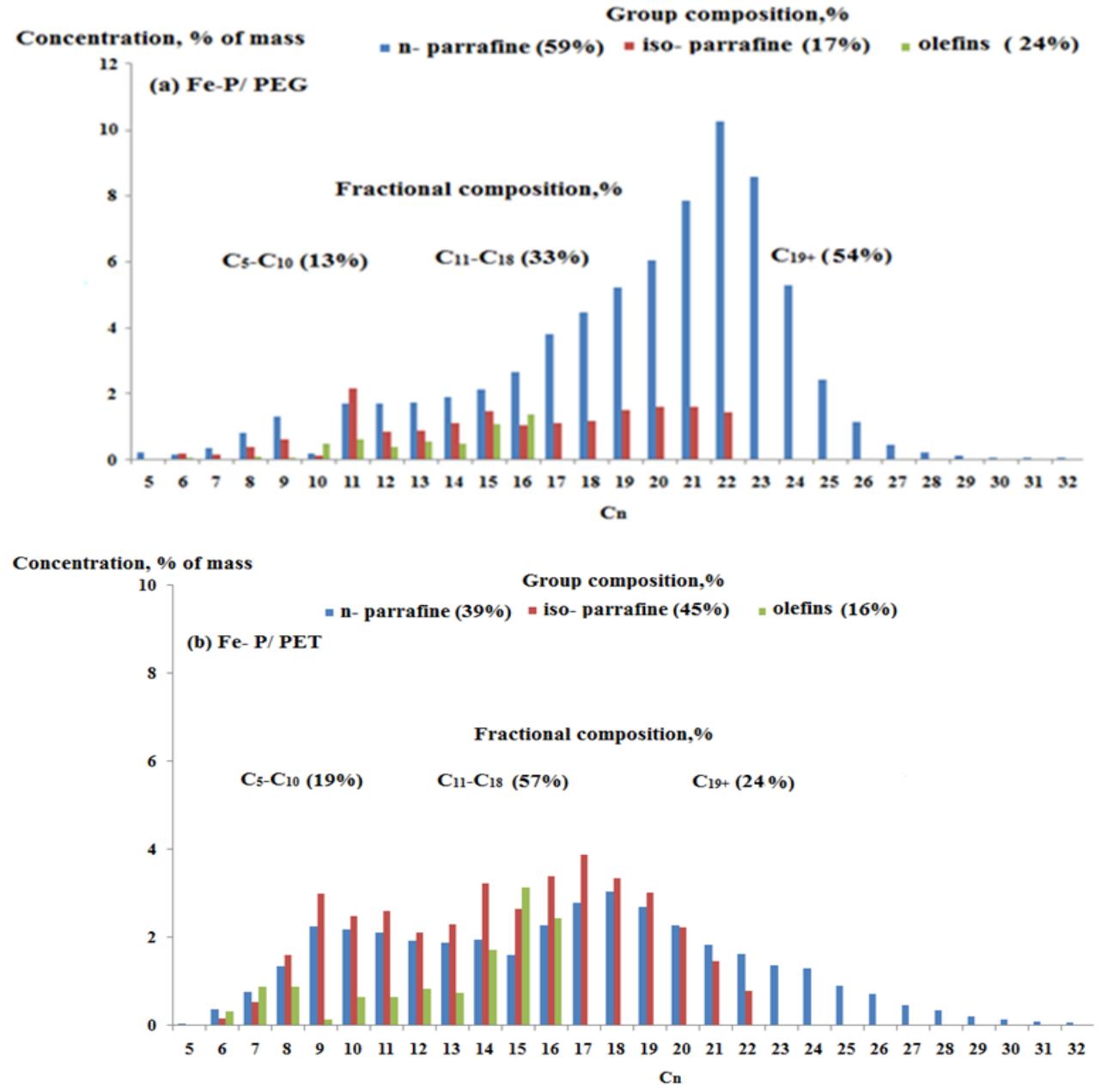


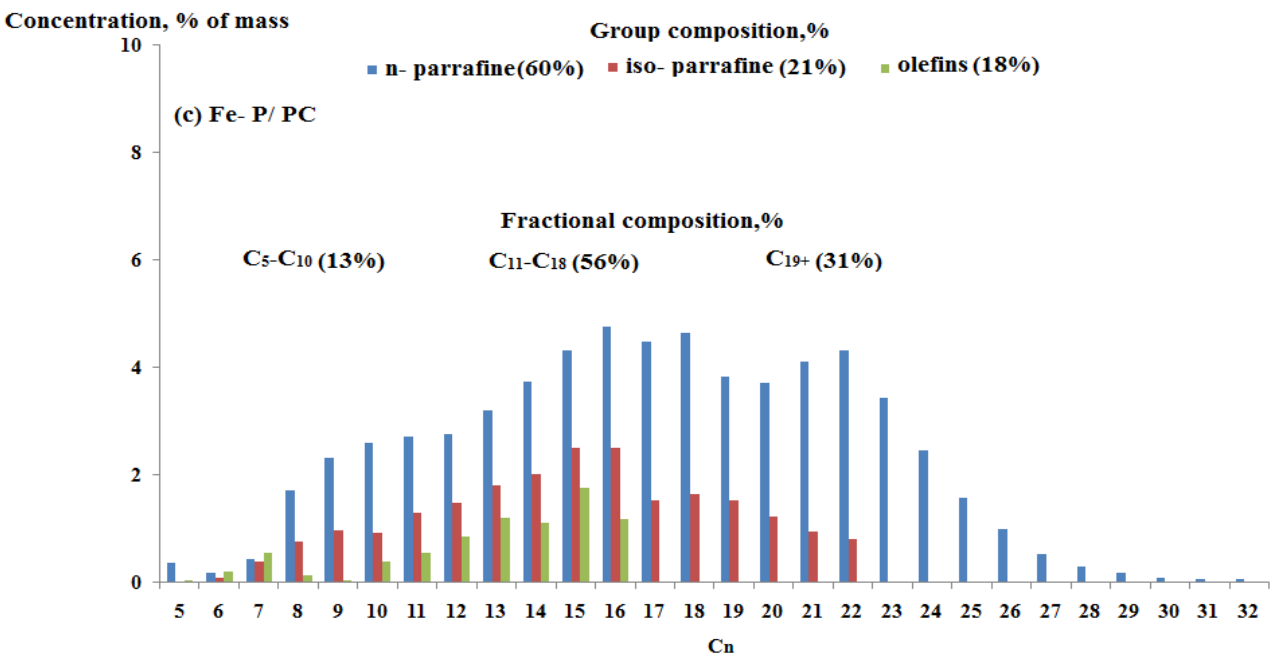

Figure 3:Composition of liquid hydrocarbons produced in existence of the systems: (a) Fe-paraffin/ PEG, (b) Fe-paraffin/ PET and (c) Fe-paraffin/ PC

Table 3. Fractional and group composition of the Fischer-Tropsch synthesis products on: (a) Fe-P/ PEG, (b) FeP/ PET and (c) Fe- P/ PC.

\begin{tabular}{|c|c|c|c|c|c|c|}
\hline \multirow{2}{*}{ Nanocatalysts type } & \multicolumn{3}{|c|}{ Group composition, \% } & \multicolumn{3}{c|}{ Fractional composition, \% } \\
\cline { 2 - 7 } & n- parrafine & iso- parrafine & olefins & $\mathrm{C}_{5}-\mathrm{C}_{10}$ & $\mathrm{C}_{11}-\mathrm{C}_{18}$ & $\mathrm{C}_{19+}$ \\
\hline (a) Fe-P/ PEG & 59 & 17 & 24 & 13 & 33 & 54 \\
\hline (b) Fe- P/ PET & 39 & 45 & 16 & 19 & 57 & 24 \\
\hline (c) Fe- P/ PC & 61 & 21 & 18 & 13 & 56 & 31 \\
\hline
\end{tabular}

\subsection{Synthesized catalyst Morphology:}

\subsubsection{Atomic Force Microscope (AFM)}

The two and three dimensional scans of AFM represents an attempt to study the surface and the morphology of the catalyst and the involvement of paraffin as well. Regard morphology of the surfaces of the prepared unwashed catalysts, appeared well regulated and have sharp tips directing upwards about 15 tips $/ 100 \mu \mathrm{m}$, whereas washing with hexane to remove the paraffin resulted in totally change of Fe-P/PEG catalyst surface (Figure 4). In all cases, paraffin dissolved leaving the surface of the stabilizing polymer more uniform or simply wavy laminated and smoothed surface (Figure 4, 5 and 6).
However, we believe the paraffin with polymer as a matrix can provide well distribution of iron nanoparticles on the surface, this of course would have a great impact on the efficiency, selectivity and conversion. Moreover, after washing paraffin has an effect to stabilize the large iron nanoparticles on the surfaces of the stabilizing polymers. While the small iron nanoparticles were removed from paraffin using hexane. After the Fe-P/ PC system washed by hexane to remove the paraffin layer, we observed the iron nanoparticles quickly coalesce with great loss in their surface depth from $57 \mathrm{~nm}$ to $27 \mathrm{~nm}$ as shown in (Figure 6) ${ }^{17}$. Finally, we can summaries the main variations as below see Table 4.

Table 4. Main variations observed of the catalysts systems before and after washing with hexane based on AFM scanned averaged data.

\begin{tabular}{|c|c|c|}
\hline Catalyst type & The initial system, particle size in nm & After washing with hexane, partical \\
\hline Fe-P/ PEG & 60 & 120 \\
\hline Fe-P/ PET & 20 & 140 \\
\hline Fe-P/ PC & 35 & 40 \\
\hline
\end{tabular}




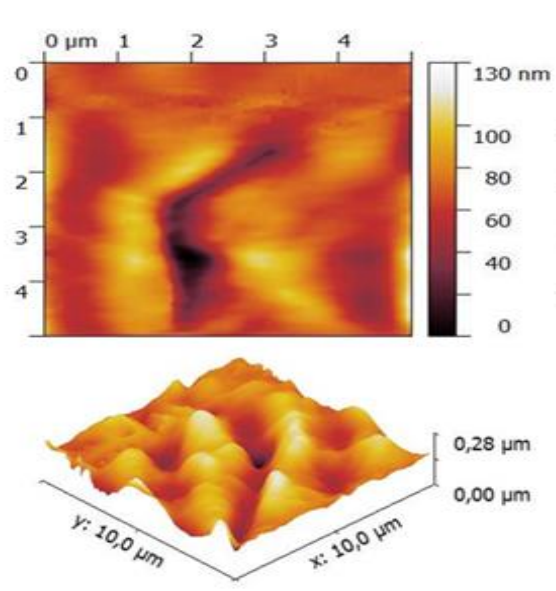

before washing with hexane
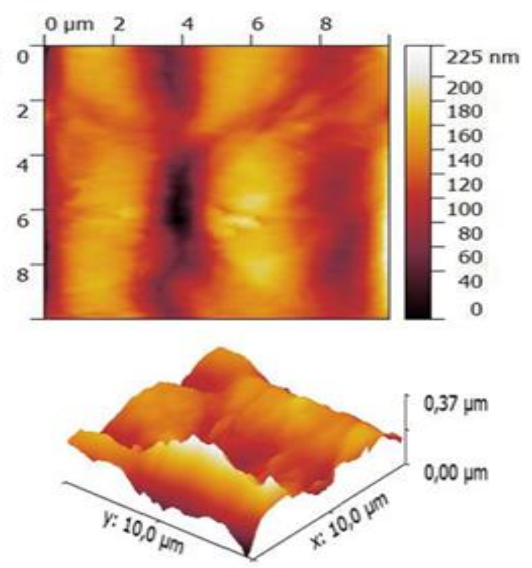

after washing with hexane

Figure 4. AFM scans for Fe-P/ PEG Catalyst's Surface, before and after washing with hexane
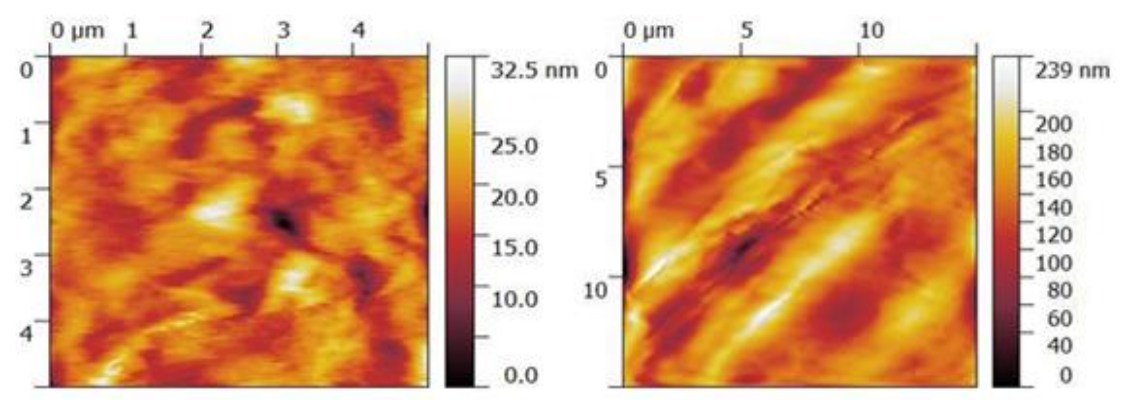

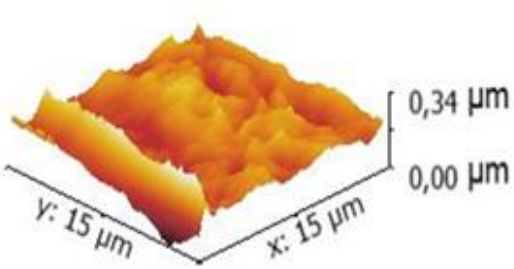

before washing with hexane

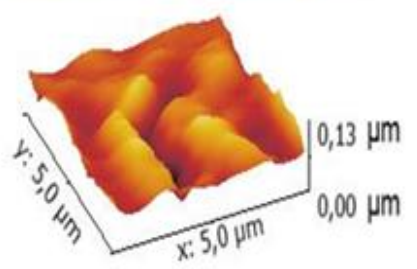

after washing with hexane

Figure 5. AFM scans for Fe-P/ PET catalyst's surface, before and after washing with hexane
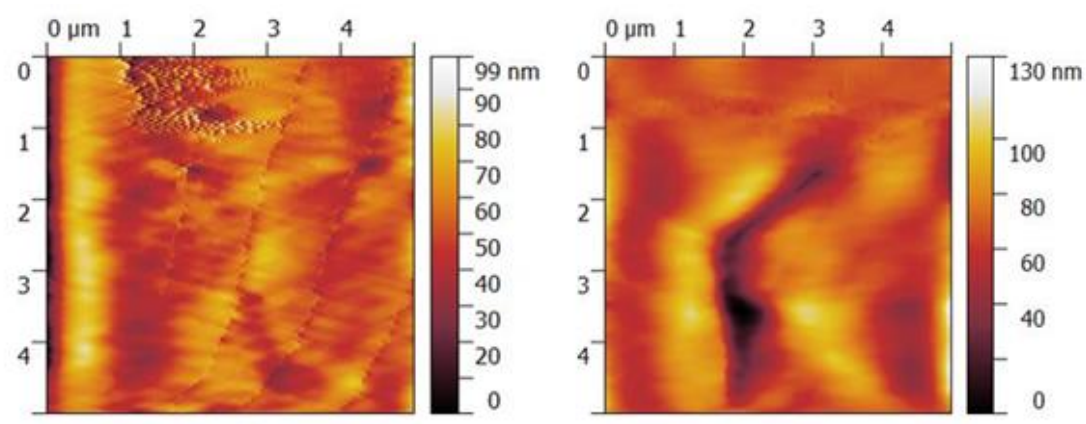

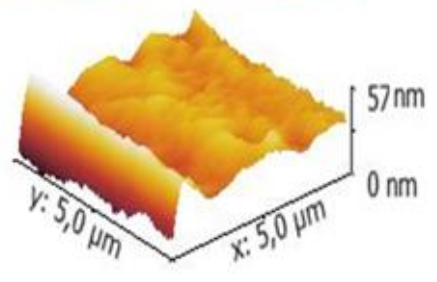

before washing with hexane

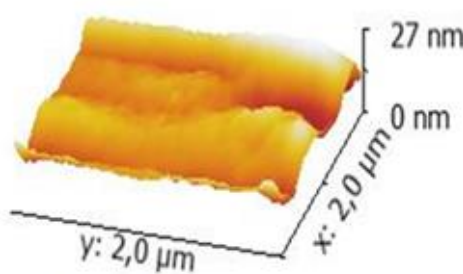

after washing with hexane

Figure 6. AFM scanning analysis of surface morphology of used system, before and after washing for Fe-P/ PC. 


\subsubsection{XRD analyses}

The XRD data indicate clearly indicate that for ironparaffin/ polymer system, the iron oxide nanoparticles are stable in paraffin and polymer suspension and responsible for the activity and selectivity of the catalyst in the Fe-paraffin/ polymer systems. The sample-based on PEG was found in both forms amorphous $(\delta$ - $\mathrm{FeOOH})$ and crystalline $\left(\mathrm{Fe}_{3} \mathrm{O}_{4}\right)$. The diffraction peaks for crystal form $\left(\mathrm{Fe}_{3} \mathrm{O}_{4}\right)$ at $2 \theta: 30^{\circ}$, $36^{\circ}, 38^{\circ}, 41^{\circ}, 43^{\circ}$ that indicates of the presence of the magnetite $\left(\mathrm{Fe}_{3} \mathrm{O}_{4}\right),{ }^{19,20,21}$ and it is responsible for the effectiveness of nanocatalysts in the Fischer-Tropsch synthesis. Additionally, the trace amount of amorphous form can be observed as highest amorphous form $\delta$-FeOOH in the PET and PC nanocatalysts (Figure 7).

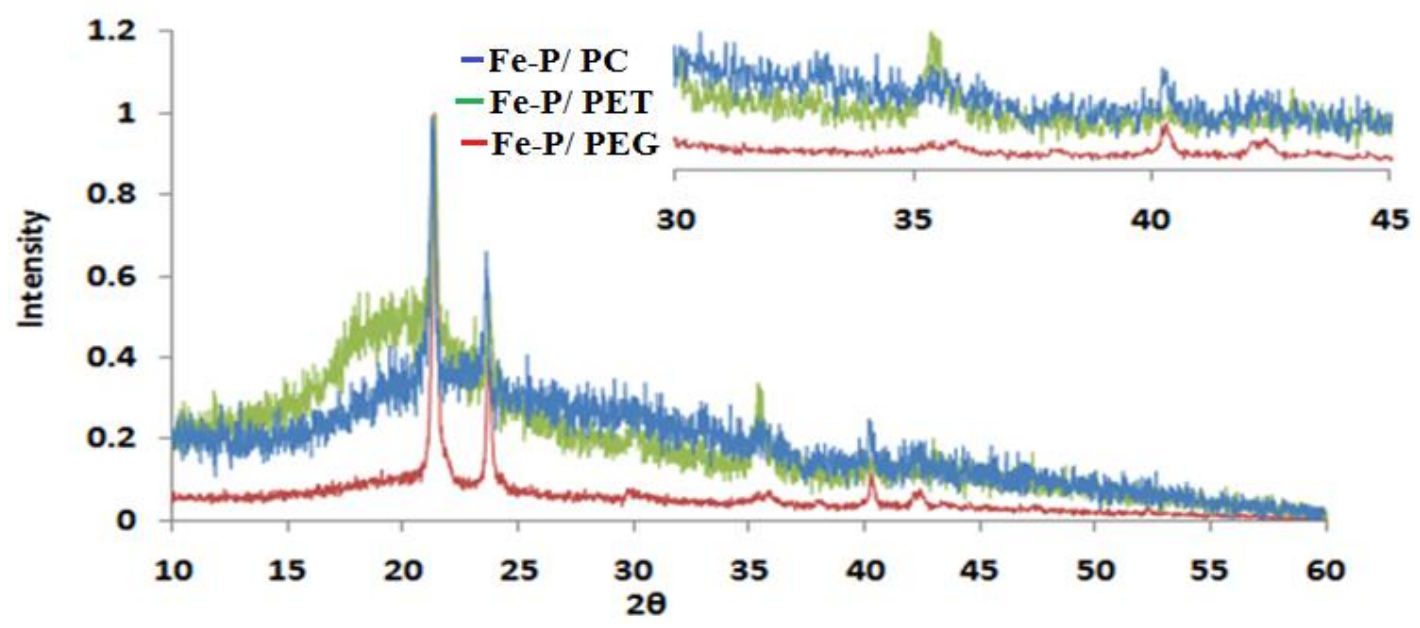

Figure 7. XRD patterns for (Nano Fe-Paraffin/ polymer) catalysts containing $10 \%$ of PEG in red, PET in green and PC in blue traces of polymers.

\section{Conclusions}

We conclude that the iron nanoparticles were affected by preparation time, this lead to form two types of nanoparticles small and large. So, we believed it is the reason for the real effects of the Fischer-Tropsch synthesis. The excellent result that obtained in the presence of the polymer as a stabilizer of nanoparticles would be suitable to be used in industry since it gave high activity and selectivity in the formation of liquid hydrocarbons. Investigation the surface of iron nanocatalysts using AFM technique confirm that the iron nanoparticles stabilized and distributed between a Paraffin and polymer. Moreover, $\mathrm{Fe}_{3} \mathrm{O}_{4}$ and $\delta$-FeOOH phases are presences in all samples as proved by XRD, and these phases are responsible for the active sites in nanocatalyst. Finally, we believe that the catalytic activities were because of a $\mathrm{Fe}_{3} \mathrm{O}_{4}$.

\section{Acknowledgments}

I want to acknowledge A. V. Topchiev Institute of Petrochemical Synthesis, Russian Academy of Sciences and so that the work was carried out by the instruments of the Institute, and which it was supported by The President of the Russian the Federation. I thank A.V. Krylov, M.V. Kulikova, V.R. Flid and Khadzhiev, S. N. for their help in this work.

\section{References}

1- J. Blanchard, N. Abatzoglou, R. Esfandabadi, F. Gitzhofer, Fischer-Tropsch Synthesis in a Slurry Reactor Using a Nanoiron Carbide
Catalyst Produced by a Plasma Spray Technique, Ind. Eng. Chem. Res., 2010, 49 (15), 6948-6955.

2- Ce. Yang, H. Zhao, Y. Hou, D. Ma, $\mathrm{Fe}_{5} \mathrm{C}_{2}$ Nanoparticles: A Facile Bromide-Induced Synthesis and as an Active Phase for FischerTropsch Synthesis, J. Am. Chem. Soc., 2012, 134 (38), 15814-15821.

3- D. Goncalo, C. Joao, V. Bruno, G. Leticia, A. Carina, A. Maria, R. Joao, V. Pedro, Noble Metal Nanoparticles for Biosensing Applications, Sensors., 2012, 12(2), 1657-1687.

4- A. Pour, M. Housaindokht, M. Irani, S. Shahric, Size-dependent studies of Fischer-Tropsch synthesis on iron based catalyst: New kinetic model. Fuel., 2014, 116, 787-793.

5- S. Ahmed, M. Ahmad, B. Swami, S. Ikram, A review on plants extract mediated synthesis of silver nanoparticles for antimicrobial applications: A green expertise. Journal of Advanced Research., 2016, 7(1), 17-28

6- Z. Wang, S. Skiles, F. Yang, Z. Yan, D. Goodman, Particle size effects in FischerTropsch synthesis by cobalt. Catalysis Today., 2012, 181, 75-81.

7- S.N. Khadzhiev, N.V. Kolesnichenko, N.N. Ezhova, Slurry technology in methanol synthesis (Review). Petroleum Chemistry, 2016, 56 (2), 77-95.

8- B.D. Gates, Q. Xu, M. Stewart, D. Ryan, C.G. Willson, G.M. Whitesides, New approaches to nanofabrication: Molding, printing, and other techniques. Chem. Rev., 2005, 105 (4), 1171-1196. 
9- A. H. Al khazraji, Influence of Iron Nano Copolymer catalysts on the liquid hydrocarbons production in the synthesis Fischer Tropsch. Journal of Global Pharma Technology. 2019 , 11(07), 827-834.

10-S. N. Khadzhiev, S. A. Sagitov, A. S. Lyadov, Fischer-Tropsch process in a three-phase system over iron-cobalt catalyst nanoparticles in situ synthesized in a hydrocarbon medium. Petroleum Chemistry., 2014, 54(2), 88-93.

11- R. Guettel, U. Kunz, T. Turek, Reactors for Fischer-Tropsch Synthesis. Chem. Eng. Technol., 2008, 31(5), 746-754.

12- M. V. Kulikova, S.N. Khadzhiev, MetalContaining Nano dispersions as Fischer-Tropsch Catalysts in Three-Phase Slurry Reactors. Petroleum chemistry., 2017, 57(6), 796-799.

13-D. A. Grigoriev, M.N. Mikhailov.; hybrid metal zeolite catalysts synthesis of Fischer-Tropsch for obtaining a fraction hydrocarbons $\mathrm{c}_{5}-\mathrm{c}_{18}$. Catalysis in the chemical and petrochemical industries., 2013, 4, 31-41.

14-M. V. Kulikova, A. H. Al Khazraji, O. S.Dement'eva, M. I. Ivantsov, V. R. Flid, S. N. Khadzhiev, Influence of dispersion medium composition on Fischer-Tropsch synthesis in three-phase system in the presence of ironcontaining catalysts. Petroleum Chemistry., 2015, 55(7), 537-541.

15-A. Bing, Ch. Kang, W. Cheng, W. Ye, L. Wenbin, Pyrolysis of Metal-Organic Frameworks to $\mathrm{Fe}_{3} \mathrm{O}_{4} @ \mathrm{Fe}_{5} \mathrm{C}_{2}$ Core-Shell
Nanoparticles for Fischer-Tropsch Synthesis. ACS Catal., 2016, 6(6), 3610-3618.

16-A. A. Mirzaei, S. Vahid, M. Feyzi, FischerTropsch Synthesis over Iron Manganese Catalysts: Effect of Preparation and Operating Conditions on Catalyst Performance. Advances in Physical Chemistry., Volume 2009, Article ID 151489, 12 pages.

17-A. H. Al Khazraji, Ph. D. Thesis, ironnanopartecles catalysts "core-shell" in the FisherTropsh reaction: synthesis, structure, properties and kinetic aspects. Moscow Technological University (Institute of Fine Chemical Technologies), Moscow, Russia (2017).

18-M. V. Kulikova, M. I. Ivantsov, M. N. Efimov, L. M. Zemtsov, P. A. Chernavskii, G. P. Karpacheva, S. N. Khadzhiev, formation features of composite materials containing cobalt nanoparticles active in Fischer-Tropsch synthesis. Eur. Chem. Bull., 2015, 4(4), 181-185.

19-A. H. Alkhazraji, O. S. Dementyeva, Z. Pastukhova, M. V. Kulikova, V. R. Flid, Comparative study of nano iron catalysts in the presence of the crude polymer matrix and their cross link polymer in the Fischer-Trophsch synthesis. Journal of Physics: Conf. Series., 2018, 1032, 1-10, 012065.

20-A. H. AlKhazraji, A. V. Krylov, M. V. Kulikova, V. R. Flid, O.Yu. Tkachenko, kinetic model for Fischer-Tropsch synthesis over nanoparticles iron catalysts with polymer matrix in a slurry reactor. Fine Chemical Technologies., 2016, 11(6), 70-77. 